\title{
Electrical Characterization of Dielectric-Barrier Discharge Reactor in Air and Argon
}

\author{
A. El-Amawy, G. El-Aragi, A. El-Zein, M. Talaat
}

\begin{abstract}
Dielectric barrier discharge Plasma (DBDP) is a type of non-equilibrium plasma that operates at atmospheric pressure. Electrical breakdown happens in many independent thin current filaments which are called micro discharges. These short-lived micro discharges have properties of transient atmospheric glow discharges with electron energies ideally suited for exciting or dissociating background gas atoms and molecules (Air and Argon). The discharge parameters such as gas gap voltage, discharge current, discharge consumed power for both Air and Argon are studied. The effect of different flow rates of Argon gas on the intensity of plasma and current signals was studied. The effect of different charging voltages on Air as the plasma photo and current filaments was studied.
\end{abstract}

Index Terms - : Dielectric barrier discharge Plasma (DBDP), non-equilibrium plasma, Argon, current filaments

\section{INTRODUCTION}

Dielectric-barrier discharge is a simple technique for generating non- equilibrium DBD plasma that operates at atmospheric pressure( 1 bar). It is found out that the breakdown of atmospheric-pressure air between planar parallel electrodes covered by dielectric material always occurs in a large number of tiny short-lived current filaments. the generation of non-thermal or cold non-equilibrium plasma at atmospheric pressure and the strong effect of the local field breakdown caused by space charge accumulation. The standard planar DBD configurations are drawn in Fig. 1[1]. As a result of the existence of at least one dielectric barrier, these DBD discharges require AC voltages for their operation. The dielectric, is an insulating material, cannot pass a DC. It has dielectric constant and thickness, in combining with the time derivative of the applied voltage, $\mathrm{dV} / \mathrm{dt}$, obtain the displacement current that can be passed through the dielectric(s).

A. El-Amawy is with the Plasma Physics and Nuclear Fusion Department, EAEA, Cairo, Egypt.

G. El-Aragi is with the Plasma Physics and Nuclear Fusion Department, EAEA, Cairo, Egypt.

A. El-Zein is with the Electrical Power and Machines Department, Faculty of Engineering, Zagazig University, Zagazig, P.O. 44519 Egypt.

M. Talaat is with the Electrical Power and Machines Department, Faculty of Engineering, Zagazig University, Zagazig, P.O. 44519 Egypt. M. Talaat is now on loan to work as an associate professor, Electrical Department, College of Engineering, Shaqra University, Dawadmi, Ar Riyadh, Saudi Arabia
To transmit current in the discharge gap the electric field must be high enough to cause the gas breakdown. In most applications, the dielectric restricts the average current density in the gas area. Therefore it acts as a ballast which, in the perfect case, does not consume energy[1]. The favourite materials for choosing the dielectric barrier are perspex, glass or silica glass, ceramic materials, and polymer layers. In high frequencies, the current limitation is less effective by the dielectric. Therefore, the DBD is normally operated between line frequency and nearly $100 \mathrm{kHz}$.

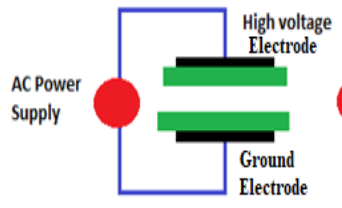

(a)

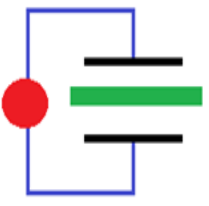

(b)

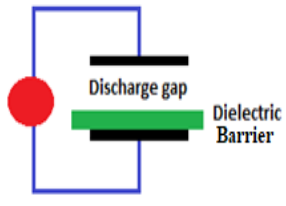

(c)
Fig 1. The DBD electrode configurations[1]

When the electric field in the discharge gap is high enough to cause a breakdown in most gasses, a large number of micro discharges are illustrated when the pressure is in order of $10^{5}$ $\mathrm{Pa}$. This is a good pressure range for ozone generation[2], excimer lamps[3], flue gas treatment, pollution control, and biomedical applications. In this filamentary mode, the plasma generates in the electrical conductivity is limited to the micro discharges. The gas in between is not ionized yet and acts as a surrounding medium to absorb the energy dissipated in the micro discharges and to collect and transmit the long-lived species[4].

The plasma concept is created by shedding high voltage energy to the gaseous state that atoms strike together and diminish their electrons [5]. The Plasma has a complicated structure, It contains a group of electrons, ions, excited and neutralization atoms, ultraviolet (UV), free radicals, thermal and infrared radiation, electric fields, and molecules [6].

From the year 2000 up till now, The Non-thermal DBD plasma is increasing attention all over the world in the biomedical field and it is presented for biomedical applications [5]-[8]. Non-thermal Plasma is a gaseous state of matter that has been ionized and considers a novel direction for the remediation of cancer, some diseases, and biomedical purposes [9]-[11]. This exciting gas contains a mix of free charges (ions, electrons), excited molecules, free radicals, and large amounts of visible, Ultraviolet (UV), and Infrared (IR) radiations and produces transient electric fields [12]. The working gas in the experiment is argon gas because it results in strongly $\mathrm{OH}$ emission comparing with Nitrogen. 
The plasma nonequilibrium in atomic argon gas is much greater than in diatomic nitrogen[13].

\section{EXPERIMENTAL SETUP}

The electrical circuit of the DBD plasma device consists of an $\mathrm{HV}$ power supply of voltage up to $15 \mathrm{kV} \mathrm{AC}$, a frequency of $50 \mathrm{~Hz}$ is connected to a variable resistance controller to adjust the input voltage and a charging resistor of $10 \mathrm{k} \Omega$. The input voltage is connected to the $\mathrm{HV}$ electrode (anode) via the HV probe of attenuation ratio 1000:1 linked to a digital oscilloscope[14]

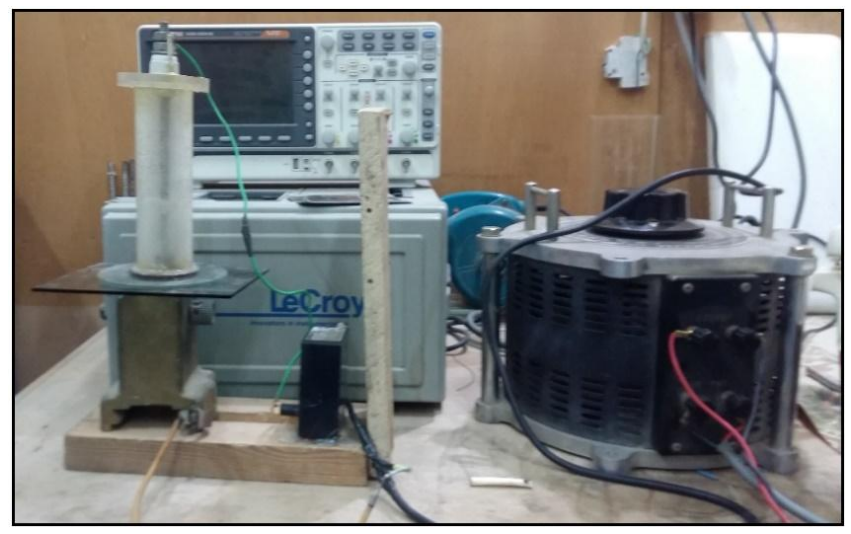

(a)

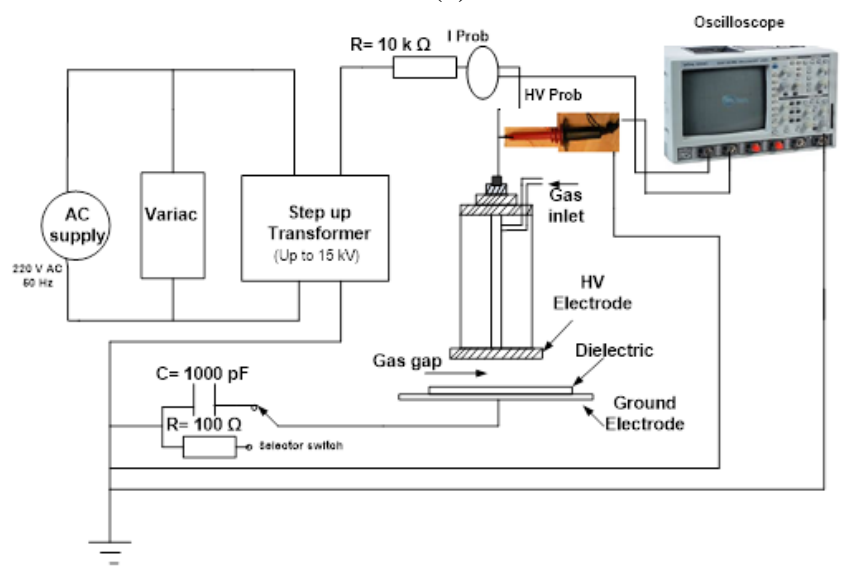

(b)

Fig 2. The Experimental setup of the DBD reactor. (a) the DBD reactor photograph, (b) the DBD reactor arrangement

Figure 2 illustrates the experimental setup of the DBD reactor which is used in this work to generate the DBD plasma and investigate the electrical characteristics and show how it works.

The DBD is generated between two parallel plane electrodes, one of them is $6 \mathrm{~cm}$ in diameter which is made of iron material ( $\mathrm{HV}$ electrode) and the other is a stainless steel sheet of dimensions $18 \times 15 \times 1 \mathrm{~mm}$ (cathode electrode). the dielectric material covers the cathode electrode in a $12 \mathrm{~mm}$ diameter of a circular glass plate. The air gap distance is 3 mm.

The HV power supply is a step-up transformer of $15 \mathrm{kV}$ of 50 $\mathrm{Hz}$ in frequency. an autotransformer variac to control the applied voltage and a ballast resistance of $10 \mathrm{k} \Omega$ for protection.

The diagnostic techniques which are used in this experiment are a 1000:1 HV probe to measure voltage, a Rogowiski coil to measure current, a digital oscilloscope of bandwidth $200 \mathrm{MHz}$, an IR thermometer to measure the plasma temperature.

\section{EXPERIMENTAL RESULTS AND DISCUSSION}

The voltage $\mathrm{V}(\mathrm{t})$ is measured using a HV probe which records the temporal variation in voltage on a digital oscilloscope. The current $\mathrm{I}(\mathrm{t})$ measured current using a Rogowski coil. Fig. 3 , Fig. 4 shows the oscillograms of the applied voltage to the DBDP reactor using the gases of air and argon at a discharge gap distance of $3 \mathrm{~mm}$.

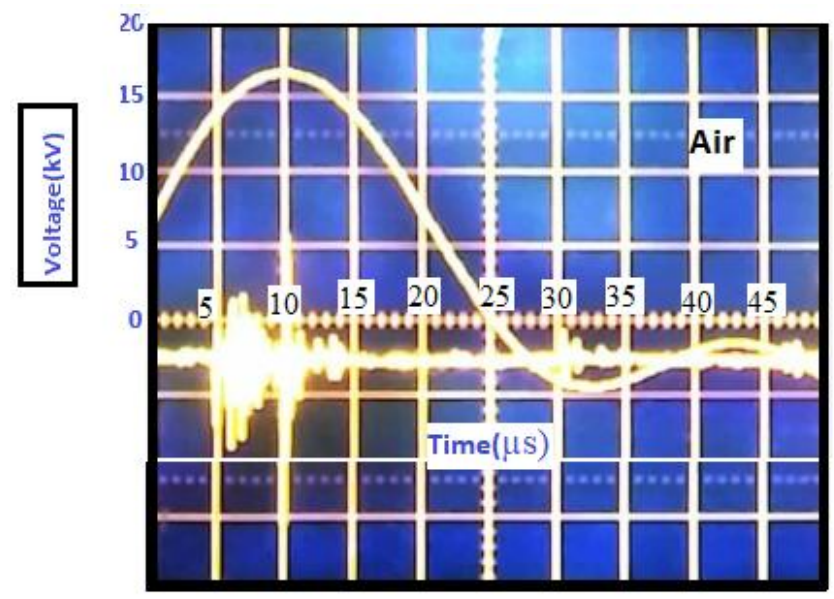

Fig. 3. The waveform of the voltage of the DBD reactor changes with time For air.

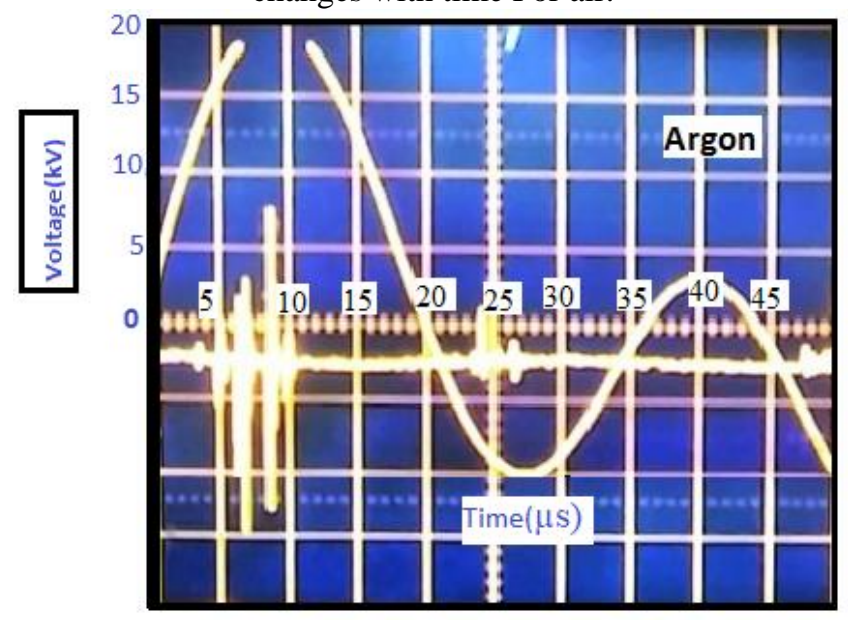

Fig. 4. The waveform of the voltage of the DBD reactor changes with time For Argon.

When the ac applied voltage of the DBDP reactor reaches the starting value, the DBD begins in the air gap inside the reactor and appears as streamers. The observed filaments are distributed randomly on the surface of the entire electrode. The streamers pass the discharge gap and diffuse on the dielectric barrier surface, generating surface charges that produce an electric field opposite to that of the applied field. Thus, after a short time (ns), the streamer action in this spot is extinguished, followed by steamers starting in another site. At the peaks values of ac applied voltage, where $\mathrm{dv} / \mathrm{dt}=0$, the displacement current on the dielectric is zero, and streamer actions stop to exist. The applied voltage connected to the anode electrode has a maximum value of $15 \mathrm{kV}$. 


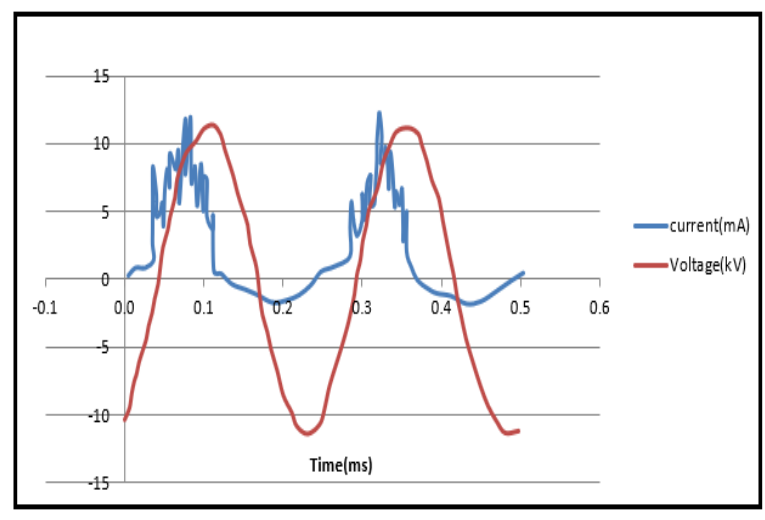

Fig. 5. Applied voltage and discharge current graphs at atmospheric pressure.

The applied voltage and discharge current are sinusoidal signals, but there are some filaments superimposed on the discharge current signal. There are current filaments for both positive cycles of the current signal. In the plasma development, the current filaments occurred at positive cycles of applied voltage, see Fig. 5. There are no filaments at a minimum of discharge current amplitudes.

Fig. 5. Applied voltage and discharge current graphs at atmospheric pressure are illustrated that every current filament corresponds to a series of micro discharges on the dielectric barrier material [15]. From Fig. 5, it could be summarized that the series of micro discharges was liberated from a circular anode electrode at every half positive cycle of the applied voltage. The area of Lissajous figures always changes with the time of the discharge. Therefore, it was very difficult to record it and to find a stable area during the experiment for both gases. The power of the plasma discharge is given by(1).

$$
\mathrm{P}=\int_{0}^{T} \mathrm{~V}(\mathrm{t}) \times \mathrm{i}(\mathrm{t}) \mathrm{dt}
$$

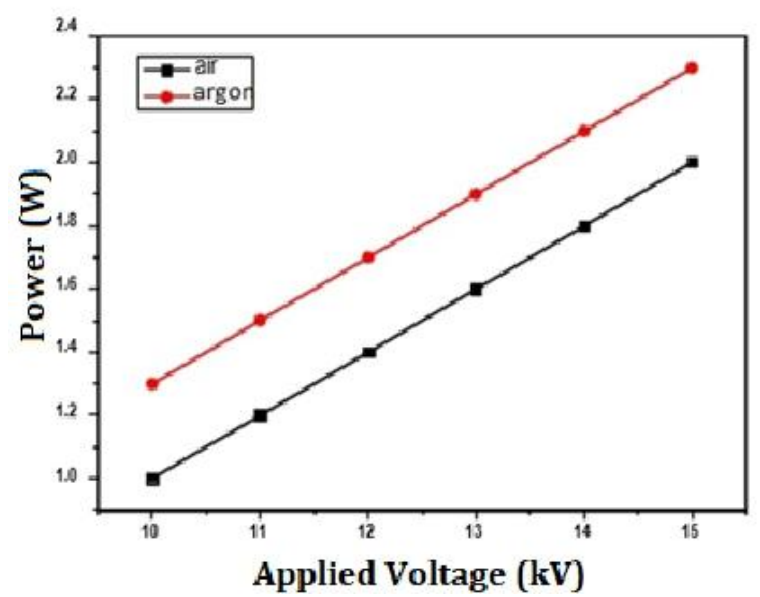

Fig. 6 Discharge power $(\mathrm{W})$ to the applied voltage $(\mathrm{kV})$ for Air and Argon.

Fig. 6 shows the average discharge power versus the applied ac voltage for air and argon which illustrated that as the applied voltage increases, the discharge power increases in a linear relationship.

Also, the photographs for the corresponding generated DBDP are shown in Fig. 7.

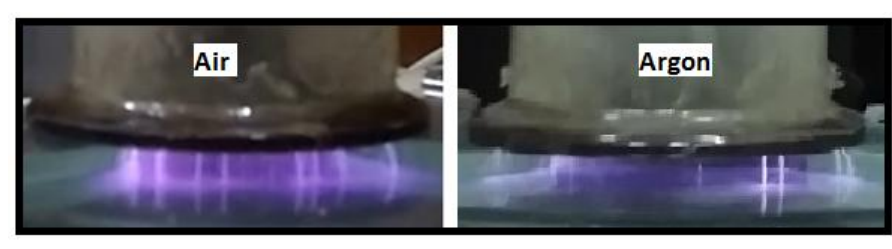

Fig.7. DBDP photographs with air and argon gas at a voltage $12 \mathrm{kV}$.

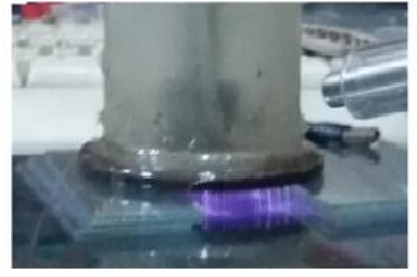

(a)

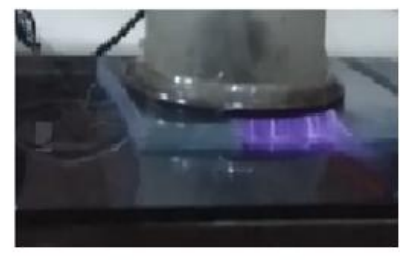

(c)

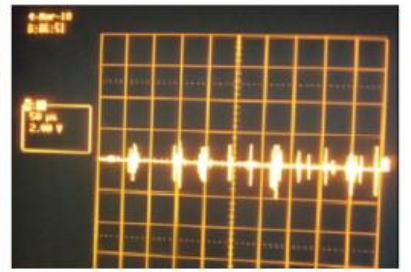

(b)

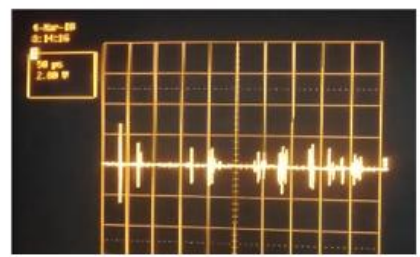

(d)
Fig.8. DBDP photographs and current signals at fixed voltage $(5.6 \mathrm{kV})$ at Argon flow rates $(5,10) \mathrm{SCFH}$.

In Figure 8, the effect of different flow rates of Argon gas on the intensity of plasma and current signals has been studied and illustrated that as increasing the Argon flow rates, the plasma intensity increased and the current filaments increased. In Figure 9, the effect of different charging voltages on Air as the plasma photo and current filaments has been studied and illustrated that as increasing the charging voltage at atmospheric pressure, the plasma intensity increased and current filaments increased.

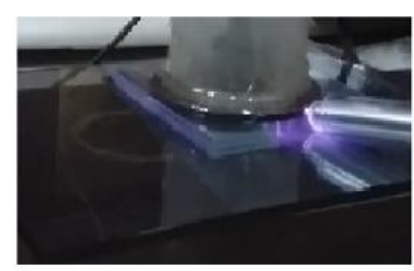

(a)

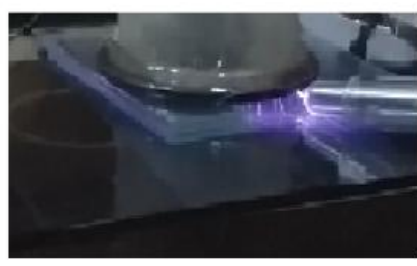

(c)

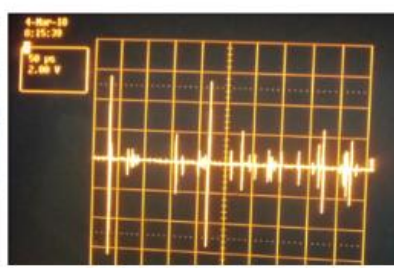

(b)

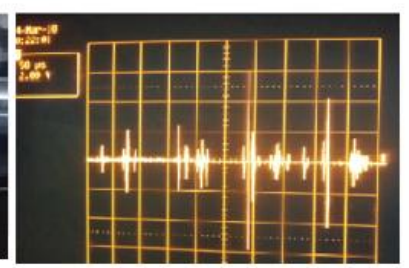

(d)
Fig.9. DBDP photographs and current signals of Air at voltages $(5.6 \mathrm{kV})$ and $(6.4 \mathrm{kV})$. 


\section{CONCLUSIONS}

- The air gap gas required a higher applied voltage at the breakdown more than that required for argon gas.

- The charge transferred per half cycle is less for air gas and highest for argon gas.

- The electrons in the DBD gas region dissipate rapidly $\cong 30 n s$, while the heavy ions remain several $\mu$ s which can be attributed to its low speed (electrons $10^{5} \mathrm{~m} / \mathrm{s}$, but ions $\cong \frac{1}{100}$ of electron speed).

- It was confirmed that the micro-discharges channels spread from the positive electrode toward the ground electrode and did not shift to an arc discharge.

- The conventional DBD using AC high voltage has a relatively low instantaneous energy input, but by using high-frequency Ultra- Short pulses to obtain highly energetic electrons, which results in an efficient formation of key radical species.

- There are many current filaments in the current waveforms. These filaments showed that the micro discharges produced on the dielectric barrier and superimposed on the current signal. The micro discharges happened before each positive half cycle of the applied voltage.

- The DBDP phenomena have been observed more luminous, clearer, and more homogenous as increasing the flow rate of gas.

\section{REFERENCES}

[1] U. Kogelschatz, "Dielectric-barrier Discharges: Their History, Discharge Physics, and Industrial Applications “, Plasma Chemistry and Plasma Processing, Vol. 23, No. 1, March 2003.

[2] U. Kogelschatz, B. Eliasson: Ozone Generation and Applications, in Handbook of Electrostatic Processes, J.S. Chang, A.J. Kelly, J.M. Crowley (Eds.), Marcel Dekker, New York (1995) 581-605

[3] K. Stockwald, M. Neiger, Contrib. Plasma Phys. 35 (1995) $15-22$

[4] F. Massines, C. Mayoux, R. Messaoudi, A. Rabehi, P. Ségur, Int. Conf. on Gas Discharges and their Applications, Swansea, UK (1992) 730-733

[5] G. Fridman, G. Friedman, A. Gutsol, A. B. Shekhter, V. N. Vasilets, and A. Fridman, "Applied plasma medicine," Plasma Process. Polym., vol. 5, no. 6, pp. 503-533, 2008.

[6] K. D. Weltmann, E. Kindel, T. von Woedtke, M. Hähnel, M. Stieber, and R. Brandenburg, "Atmospheric-pressure plasma sources: Prospective tools for plasma medicine," Pure Appl. Chem., vol. 82, no. 6, pp. 1223-1237, 2010.

[7] G. Y. Park et al., "Atmospheric-pressure plasma sources for biomedical applications," Plasma Sour. Sci. Technol., vol. 21, no. 4, pp. 043001-043022, 2012.

[8] K.-D. Weltmann, M. Polak, K. Masur, T. von Woedtke, J. Winter, and S. Reuter, "Plasma processes and plasma sources in medicine," Contrib. Plasma Phys., vol. 52, no. 7, pp. 644-654, 2012.

[9] G. Fridman, A. Shereshevsky, MM. Jost, AD. Brooks, A. Fridman, A. Gutsol, V. Vasilets, G. Freidman, "Floating electrode dielectric barrier discharge plasma in air promoting apoptotic behavior in melanoma skin cancer cell lines". Plasma Chem Plasma P. 2007;27(2):163-176.

[10] G. Fridman, M. Peddinghaus, H. Ayan, A. Fridman, M Balasubramanian, A. Gutsol, A. Brooks, G. Friedman, Blood coagulation and living tissue sterilization by floating-electrode dielectric barrier discharge in air. Plasma Chem. Plasma Process. 2006, 26, 425-442.

[11] G.C. Kim, G.J. Kim, S.R. Park, S.M. Jeon, H.J. Seo, F. Iza, J.K Lee, Air plasma coupled with antibody-conjugated nanoparticles: A new weapon against cancer. J. Phys. D: Appl. Phys. 2009, 42 , 032005:1-032005:5.

[12] B. Adhikari and R. Khanal, "Introduction to the Plasma State of Matter," the Himalayan Physics, vol. 4, no. 4, 2013.
[13] Y. Xian, X. Lu, Z. Tang, Q. Xiong, W. Gong, D. Liu, Z. Jiang, Y Pan. Optical and electrical diagnostics of an atmospheric pressure room-temperature plasma plume. Appl Phys. 2010;107:063308.

[14] A. El-Zein, M. Talaat, G. El-Aragi, and A. El-Amawy.," The Characteristics of Dielectric Barrier Discharge Plasma Under the Effect of Parallel Magnetic Field.” IEEE Trans. Plasma Sci., vol. 38, 12th Mar. 2020

[15] H.-E. Wagner, R. Brandenburg, K. V. Kozlov, A. Sonnenfeld, P. Michel, and J. F. Behnke, "The barrier discharge: basic properties and applications to surface treatment," Vacuum, vol. 71, no. 3, pp. 417-436, May 2003.

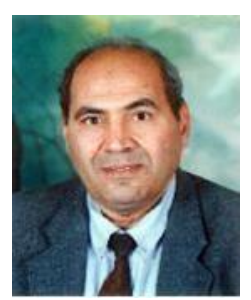

\section{BIOGRAPHIES}

A. El-Zein (Professor) was born in El-Dakahlia, Egypt in 1948. He received the B.Sc. and M.Sc. degrees from the Faculty of Engineering, Cairo University, Egypt in 1971, and 1977 respectively, and the Ph.D. degree from Ain-Shams University in 1985. Now he is an Emeritus Professor at the Electrical Power and Machines Department, Faculty of Engineering, Zagazig University. The research interest covers different types of high voltage insulation, breakdown of dielectric materials (gasses, liquids, and solids), plasma sources, and applications

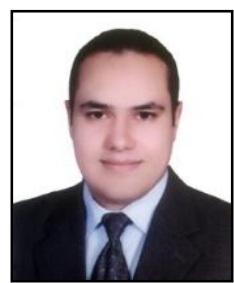

M. Talaat(Associate Professor) was born in El-Sharkia, Egypt in 1979. He received the B.Sc., M.Sc., and Ph.D. degrees from the Faculty of Engineering, Zagazig University, Egypt in 2000, 2005, and 2009 respectively, he is an Associate Professor at the Electrical Power and Machines Department, Faculty of Engineering, Zagazig University, Egypt, and now he is Associate Professor at the Electrical Engineering, Shaqra University, Dawadmi, Ar Riyadh, Saudi Arabia. The research interest covers different types of High voltage application, Electric fields, Plasma science, Renewable energy, Mathematical calculation, and Computer programs using simulation models

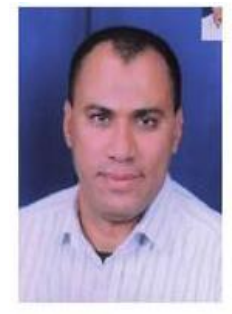

G. El-Aragi is (Associate Professor) was born El-Kalubia, Egypt in 1960. He received the B.Sc degree from El-Azhar University, Faculty of Science in 1984, the M Sc. Degree in 1990, and Ph.D. in 1994 in physics. He is the head of the Plasma and Nuclear Fusion Department, N. R. C. (Nuclear Research Center) Egyptian Atomic Energy Authority, Cairo, Egypt. His research interest covers plasma science and nonthermal plasma sources and applications.

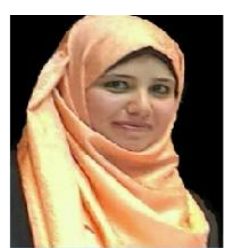

A. El-Amawy (Assistant Lecturer) was born in El-kalubia, Egypt in 1985. She received the B.Sc degree from Shoubra Faculty of Engineering, Banha University, Egypt in 2007 and the M.Sc. degree from the Faculty of Engineering, Zagazig University, Egyp in 2015, She is Assistant Lecturer at the EAEA (Egyptian Atomic Energy Authority), NRC (Nuclear Research Center) in 2017, Egypt, and She works at the EAEA from 2009 until now. She works at the Plasma and Nuclear fusion department. The research interest covers High voltage application, Plasma science, Non-thermal Plasma sources, and applications. 